\title{
Research and Practice in Voice Studies: Searching for a Methodology.
}

\section{Daron Oram BA MA - Senior Lecturer in Voice, RCSSD, London (UK).}

\section{Introduction}

This article proposes a Practice-as-Research paradigm in response to a growing need for voice trainers in higher education to become researchers. I will examine the shifting patterns of teaching and research practices within theatre-focussed higher education and use, as case study, my experiences teaching at The Royal Central School of Speech and Drama (hereafter known as Central). I will then address the question of how voice teachers might produce the types of research outputs demanded by higher education institutions.

In the UK, Voice Studies is a growing subject. It has been taught at Masters Level for just over a decade. Prior to this, the highest level of qualification was a Post Graduate Diploma (PGDip), which reflected the purely vocational training on offer. At the level of scholarly research arts based ${ }^{1}$ Voice Studies, is less well established, although there is gathering momentum in this area. Last year saw the inaugural symposium of the Centre for Interdisciplinary Voice Studies in the UK, which, according to their website 'seeks to negotiate links and connections in the slippages between philosophical discourses, the praxis and pedagogy of training and using the voice, and the act of experiencing 'the voice' - in its many and varied forms.' (https://interdisciplinaryvoicestudies.wordpress.com/2013/08/)

This centre's aim to negotiate the 'slippages' between philosophical discourse, praxis and pedagogy is particularly relevant here. In the struggle to articulate the subject of voice, it is possible that the discussions might be limited to frameworks used by other more established subject areas, such as those that use qualitative research methodologies drawn from the social sciences or the quantitative scientific model. I shall argue here that the emergent methodology of arts-based Practice as Research ( $\mathrm{PaR}$ ) not only offers voice practitioners a chance to document their studiobased practices; it ultimately provides an opportunity to advance the nascent field of Voice Studies.

Although this paper might seem to have immediate relevance only to UK practitioners, it should be useful to practitioners internationally especially from Australia, parts of continental Europe, and Canada, where comparable PaR-like methodologies are being developed. ${ }^{2}$

PaR may have originated in Finland in the mid 1980s and was emergent in the UK about that time. Australia has become a significant force in developing PaR [where it is known as Practice Led Research] and there are strong pockets of activity in Nordic countries, South Africa, France and (particularly francophone) Canada. (Nelson. 2013, 11)

\section{Context}

The emergence of research across HE in the UK demands an understanding of the seismic changes imposed by successive governments over the last generation. Actor training was once provided by privately run drama schools, such as Guildhall, RADA, Central and LAMDA, while universities took a more academic approach, with varying degrees of practice, through Theatre Studies and Drama. These subjects were joined later by degrees in Performance Studies. Higher education at the time was provided free to all. Beginning with the 1962 Education Act (http://www.legislation.gov.uk/ukpga/1962/12/pdfs/ukpga 19620012 en.pdf) all Local Education Authorities (LEAs) were required to provide maintenance grants to cover tuition fees and living costs for those attending University. LEAs also had funds available to support some students to attend the privately run drama schools. 'In 1990, the first UK student loan scheme was implemented' (Wyness. $2010,8)$ and the Conservative government froze grant payments. Over successive governments the balance of grants to loans shifted until, in 1998, the grant system was 'cut, before being abolished 
the following year, and maintenance loans were extended to all students.' (10) The shift of funding from grants to loans had a direct impact on the small privately run drama schools. Traditionally, students from less wealthy backgrounds attending these schools had been able to access the discretionary funding from their LEAs; however, this money dwindled as the shift to a loans-based system was implemented. These new loans were only available to those studying for a degree and, historically, drama schools did not award degrees. In order to enable their students to access this new loans-based funding stream, drama schools began to offer degrees that were validated by partner Universities.

At this stage, student loans only covered part of University tuition fees, with the rest being paid for by direct government funding. The funding situation continued to shift over subsequent years and many drama schools sought to gain some security by integrating more fully with universities. For example, East 15 Acting School became part of the University of Essex, Central School of Speech and Drama joined the University of London, and Guildford School of Acting became part of the University of Surrey. Central government funding for education within the Arts and Humanities eventually came to a full stop after the Browne report in 2010 (Browne, J. 2010) and was replaced completely by loans. 'The UK coalition government [...] decided that from October 2012 there would be a cap [on loans] of $£ 9000$ per annum in England.' (Wilkins, Shams \& Huisman. 2013, 121)

Because of this cap to income, resources within drama schools are tight. However, for those drama schools that are now part of universities, there is an additional source of finance available: Quality Research Funding. As well as direct funding for specific research projects, Universities can also receive funding via the Higher Education Funding Council for England (HEFCE) for Quality Research (QR). Access to this additional QR funding is highly competitive and is awarded over an approximate six-year cycle. The level of funding is based on an audit of research outcomes known currently as the Research Excellence Framework (REF). Using this framework, an institution's research outputs are given a rating of one to four stars. The REF website states that a four-star rating is given to research that is of a "Quality that is world-leading in terms of originality, significance and rigour." (http://www.ref.ac.uk/panels/assessmentcriteriaandleveldefinitions/). In short, schools that wish to access this QR funding are looking to their faculties to produce "REF-able" research outcomes. This can mean that a voice teacher who trained in a non-academic acting school, and who may lack a bachelor's degree, may well be requested to develop academically viable research ${ }^{3}$.

Because I completed my first degree, a BA in Drama, at a University and not an acting conservatoire, I have some experience with academia. After some additional actor training, I attended Central where the Masters in Voice Studies involves a mixture of practice and some elementary research. It was a few years ago that I joined the faculty at Central and part of my contract there is to undertake research. I initially felt unsure how to proceed with this research, despite the academic experiences cited above my voice career had been solely practice based and I did not feel equipped to engage with academic theory at an advanced level. Not only did I feel out place with research, but I also felt a tension between the need to develop research that the REF would rate highly and the desire to continue to develop myself as a creative practitioner training high-level acting students for the profession. The tension here is not between me and my job description, I am pleased to have the opportunity to be able to work on research and teaching, rather, the tension comes between my teaching, which has a vocational training aim tied to the demands of the acting profession, and the research, which is necessarily scholarly and tied to the demands of academic frameworks such as the REF.

\section{Implications for voice teachers.}

I do not question the long-standing requirement for faculty in Higher Education to be asked to produce quality teaching and research. However, traditionally in the UK, faculty in Higher Education have come through a career path that has been research based. The issue at hand here, 
stems from acting conservatoires being subsumed into these HE structures. In conservatoires most acting faculty come from a practice background and teach with a focus on the needs of the profession. The type of daily research that informs quality teaching-preparing for classes/productions, developing curricula and practice etc. - is not scholarly research. In practical terms, for the University, it does not fit with the REF definition of Research as detailed on their website.

1. For the purposes of the REF, research is defined as a process of investigation leading to new insights, effectively shared.

2. It includes work of direct relevance to the needs of commerce, industry, and to the public and voluntary sectors; scholarship; the invention and generation of ideas, images, performances, artefacts including design, where these lead to new or substantially improved insights; and the use of existing knowledge in experimental development to produce new or substantially improved materials, devices, products and processes, including design and construction. It excludes routine testing and routine analysis of materials, components and processes such as for the maintenance of national standards, as distinct from the development of new analytical techniques. It also excludes the development of teaching materials that do not embody original research. [My italics] (REF. 2011, 48)

There is, in addition to the REF requirements, a further issue. Drama schools that have partnered with a University have often adopted that University's protocol for faculty progression. In practice this often means that, whilst reflective approaches to teaching that lead to improved curricula and pedagogy, will be recognised as good practice and be reflected positively in the allimportant student satisfaction surveys, it will have a limited effect on career advancement or promotion, which is more often tied to research outputs and potential REF star rating.

\section{Exploring practice-based research models for Voice Studies.}

As mentioned at the start of this paper, arts-based Voice Studies has yet to establish itself firmly within the field of Arts and Humanities. There is, though, growing momentum in this area. Ben Macpherson and Konstantinos Thomaidis the organisers of the interdisciplinary voice symposium mentioned in the introduction are working towards the first publication of a new journal, The Journal of Interdisciplinary Voice Studies, which will be published by Intellect books in 2016. They are also editing the forthcoming Routledge publication Voice Studies: Critical Approaches to Process, Performance and Experience. These developments will be vital in establishing the subject further. Many of the contributors to the forthcoming book have a distinguished practice base as well as a university research background; however, I am interested here in how practitioners, whose experience has been solely practice based, can engage with a research agenda alongside and indeed collaboratively, with such colleagues: how can conservatoire based practitioners, now sitting within this HE structure, contribute to the dialogue within, and growth of, the subject and meet the research expectations of their employers?

With the move, in recent years, to masters level teaching of voice studies and the opening up of practice based PhDs, there is now a viable academic progression for the voice practitioner. However, there will still be many whose careers take a more vocational path that eventually leads back into $\mathrm{HE}$ and that is certainly the case for the majority of University Conservatoire faculty at present. I believe that there is considerable new knowledge being developed at the forefront of practice within some conservatoire training and that this new knowledge may justifiably be framed as research. The challenge is to find a methodology that can frame that work in a form that is acceptable at a scholarly level.

A research methodology often used by students of Voice Studies at Masters level is Action Research, which is commonly used in the field of education. It is a process of planning, reflection, 
action, and monitoring. It is an inquiry-based methodology that asks a specific question, such as 'what is the most effective way to teach the IPA to undergrad actors?' This cycle of action and reflection is core to good teaching practice and should be recognisable to most practitioners.

There are two main problems when it comes to Action Research as a methodology for Voice Studies at an advanced scholarly level. First, is that Action Research is itself still fighting for recognition. In her article in the Journal of Geography in Higher Education Natascha Klocker says:

The literature examining PAR [Participatory Action Research ${ }^{4}$ from a doctoral student's perspective is sparse....and oftentimes despondent about the potential for PAR and PhDs to coexist...The wider PAR literature is critical of the modern, neo-liberal university sector and frequently portrays the goals of PAR and academia as antithetical. (Klocker. 2012, 149)

Secondly, the outputs of a pedagogically focussed Voice Studies discipline would inevitably lean toward the how to publications that are already so plentiful. These voice handbooks, whilst valuable resources in developing practice, do not fit within the REF criteria outlined above.

In fact, when these publications are scrutinised by some academics they can easily be misread or deconstructed through theoretical lenses. Kristin Linklater anticipates this danger when she says 'I have tried to capture the work that Iris Warren said should never be written down. It is intended, by its nature, to be conveyed orally, and it is dangerous to limit and define it in printed words.' (Linklater. 1976, 4)

In 1996 in the New Theatre Quarterly, Sarah Werner, a feminist theatre scholarresponding to the voice books of Linklater, Berry, and Rodenberg-argued that the "natural" and "free voice" approaches limited actors' abilities to question the politics of those texts (Werner. 1998). Jane Boston discusses this further in a recent VSR article and notes that 'In examining the training, she [Werner] chose to examine only the training texts, not the studio work.' (Boston. 2014, 132). In the same year Richard Paul Knowles took a materialist literary criticism approach to six voice books by the same authors. It is almost ironic that, after reading her voice books as 'cultural productions', Knowles concludes that Cicely Berry's books 'function effectively to inhibit politicised readings and political dissent.' (Bulman. 1996, 99). A similar reading of Linklater's Freeing the Natural Voice leads him to conclude that 'in attempting to transcend cultural conditioning en route to "the atmosphere of universal experience" she allows for the effacement of cultural and other kinds of difference and is in danger of throwing out the baby with the generalizing wash of her rhetoric.' (100)

From my own multiple experiences of seeing Linklater and Berry give talks and teach, I can affirm that they are both neither a-political nor generalised. This literary attitude to writings about theatre practice can be seen as a regrettable, though understandable, extension of the predominant attitude to play texts-particularly those of Brecht and Shakespeare-within many Universities during the $20^{\text {th }}$ Century. Cicely Berry recognises this when she says that 'academic work has taken Shakespeare from us. People look up the meaning of everything. But in Shakespeare's day, only $8 \%$ of people could read. They got the meaning through sound.' (Guardian, $24^{\text {th }}$ July 2011) However, whilst some scholars may struggle to engage with practice, it is also the case that many practitioners struggle to engage with scholarly theory. This is not irreconcilable and there is much to be gained from a dialogue which engages both sides and is ultimately necessary given the context outlined above.

Alfred Korzybski's premise that "the map is not the territory" is central to my own practice and it may provide the foundation for a rebuttal of academic deconstruction of practice and could lead towards a potential dialogical solution. As a voice teacher, I am very aware that the dried ink on the page, the written text-or map in Krozybski's metaphor-is not the image, is not the character or the play itself, and that we have to dig below that to unearth the lived experience behind the words. And yet, the very books that guide voice practitioners in this process are, in the examples above, being read as if they are the territory, as if they are the work itself. In order to respond to this 
Voice Studies is faced with a need for an academically acceptable methodology of research, situated within the field of arts practice, that is neither purely theoretical, divorced from the practice, nor purely practice based and open to misguided academic deconstruction. Practice as Research offers a solution.

\section{Practice as Research and Arts-Based Voice Studies.}

Practice as Research has been developed within the arts and does not require the co-opting of qualitative or scientific methodologies from other academic fields. PaR is a research methodology that brings together a range of knowledges. This includes the knowledge held in the how to voice manuals, along with the knowledge of related academic fields that touch on Voice and, importantly, it also includes the embodied knowledge inherent in artistic practice itself. In other words, we can use our maps, the theories of how the maps are used and produced, and the embodied experience of being on the ground, in the territory.

Practice as Research fits the needs of voice practitioners working within the academy and could help to define the academic field of arts-based Voice Studies. The PaR model recognises that some knowledge lives in the body experientially in a way that defies linguistic definition and explanation. For example, the sense of connection/authenticity I experience when breath, feeling, vibration and word meet is knowledge in and of itself. The words that often emerge in the studio in relation to this experience, such as 'truth', 'authentic', 'presence', are much contested in theoretical discourses. An example of this is Cormac Power's book Presence in Play: A Critique of Theories of Presence in the Theatre, which discusses the question of presence from a variety of performance studies perspectives. In his writing he makes reference to theoretical issues of presence across a range of work, from the traditional "making present" of classical theatre to the literal "being present" of performance art. PaR, however, opens up the possibility of evidencing the practical experience of presence itself. It offers voice practitioners the chance to join an existing tradition of scholarly researchers, where it is possible to define terms like 'presence' in relation to practice as much as theory.

PaR is well established in the UK. The recent panel report relating to Performing Arts on the REF 2014 website stated that 'UK universities and conservatoires maintain a position of international leadership in the development of PaR' (http://www.ref.ac.uk/media/ref/content/expanel/member/Main\%20Panel\%20D\%20overview\%20r eport.pdf).

There is evidence enough to recognise that we stand at a pivotal moment in the history and development of research. Practice-led researchers are formulating a third species of research, one that stands in alignment with, but separate to, the established quantitative and qualitative research traditions. (Brad Haseman quoted in Nelson. 2013, 22)

The model for PaR that I am drawing on here is presented by Robin Nelson in Practice as Research in the Arts: Principles, Protocols, Pedagogies and Resistance (2013). There are numerous other publications relating to PaR, some of which are cited below.

Nelson's model offers a way of understanding PaR that holds great potential for voice practitioners. His model divides into three areas of knowledge; "Know-how", "Know-what" and "Know-that" (37) and it allows for theory to emerge through the interaction of reflective arts practices and related theoretical discourses. Looking at these three areas from a voice perspective can give us a clearer sense of this.

\section{Know How:}


Know how is embodied knowledge. I know how to speak a line of poetry whilst connecting to the images held within the text. The sense of connection and communication in this instance is something that I feel and, through experience, I know that this can also be felt by an audience. These feelings are somewhat inchoate and present a challenge if we choose to document them solely through a written research output, such as a journal article. However, by choosing to evidence the physical experience as part of the research process, the embodied knowledge can begin to speak for itself. This knowing through the body, a psycho-physical mindfulness, has been part of much voice teaching for some time and, through PaR, it becomes a vital part of the research evidence. Robin Nelson quotes the Hungarian polymath Michael Polanyi, 'By elucidating the way our bodily processes participate in our perceptions we will throw light on the bodily roots of all thought, including man's highest creative powers.' (42-3)

\section{Know What:}

Nelson says that one of the key challenges of $\mathrm{PaR}$ is to make the tacit more explicit and this is done through reflective practice. The knowledge produced by this is what he terms know what. Returning to my example, I developed the embodied know how to speak a line of poetry and connect to imagery through a process of reflective analysis. This included journaling my practice, and discussing my work with peers, teachers and students. It has also been informed by the various lineages and methods of voice teaching that I have experienced. Providing evidence of these methods and processes helps to make the embodied know how more explicit. This process also has the additional advantage of bringing the previously dismissed how to voice practice publications into the research arena in a way that is much harder to deconstruct as they are directly linked to the practice itself.

\section{Know That:}

Nelson refers to this as 'outsider knowledge'(37). This knowledge might include the work of philosophers or performance studies academics. So, for instance, I have been influenced by my reading of Power's account of presence in the aforementioned book. His concepts of making present and being present have fed into classes where I teach the speaking of poetry. In these classes I ask the students to experience the difference between delivering a rehearsed performance of a text and speaking the text as a live, in the moment, dialogue with the audience. This interaction between my practice and a wider theoretical discourse, or "know that", has shifted the language of my teaching and helped to develop a new perspective on the work. In short, I have moved from a language that refers to the presentation of poetry, i.e. the delivery of the imagery, structure, thoughts and ideas contained in the poem, to a process that takes all of this work on the text and places it very consciously in the live context of performance. This context allows for a moment to moment dialogue with the audience, whereby the content of the poem is informed by the lived experience of speaking it with that audience at that time. This eventually informs an approach to dramatic text

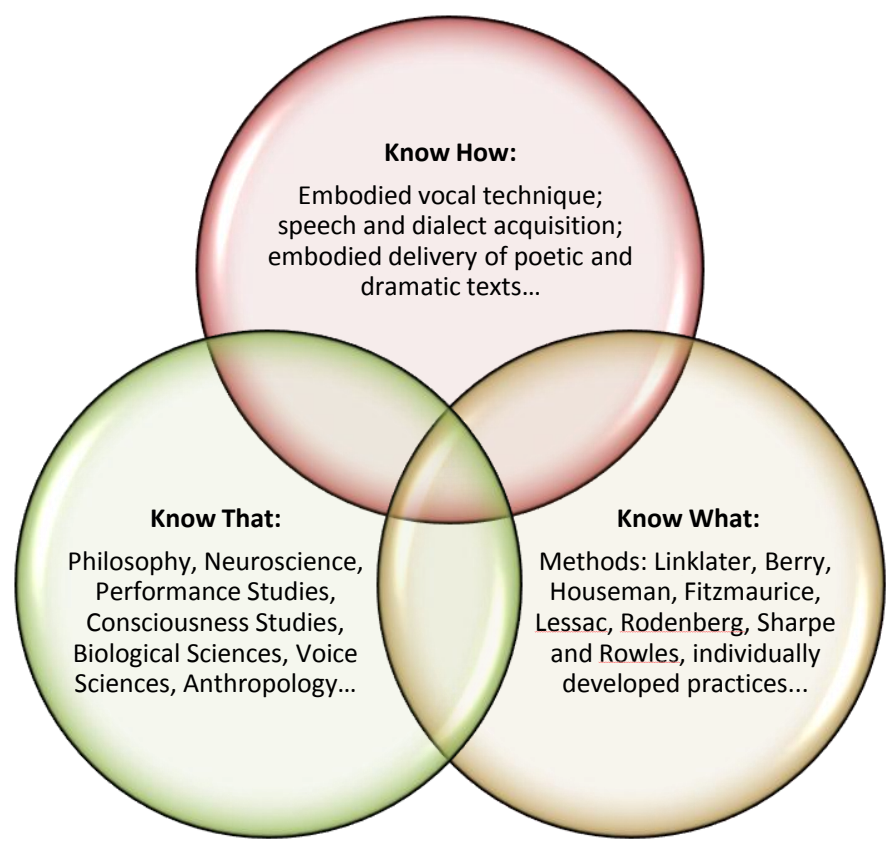
that effaces the dichotomy of character and theatre timeframes and allows for a collaborative realisation of the play between actor and audience.

For ease of communication it is possible to re-imagine Nelson's method as a model for voice studies that can be represented as a Venn diagram. The theory that emerges out of the research in Voice Studies cannot be seen by examining one area in isolation but emerges at the central area of crossover. 
Nelson uses the term resonances for these areas of crossover. Resonance, as a concept, is particularly apt for Voice Studies and gives a sense of interaction that can even allow for emotional content-something that the mathematical diagram here fails to portray.

Nelson's book gives a detailed explanation of the processes of PaR and he places the methodology within a clear philosophical framework. Some key points to draw from this are:

- $\quad$ Not all practice is research, but inquiry-based practice can be.

- $\quad$ Research should aim to produce new insights.

- $\quad$ Outputs generally include: the creative work/practice itself and some complementary writing. Creative work/practice is often documented on film and the complementary writing should locate the practice within its lineage and also show how the 'ideas circulating in the practical investigation might be clarified in the discovery of resonances with other research enquiries expressed in words.' (32)

Nelson also refers to the "rhizome model" of thought, which "lends itself to the multiple strands [of investigation] without hierarchy in contrast to the deep [tap root] mining within a linear tradition' (54) of academia. The rigor in PaR comes from how the particular strands of thought, practice and reflection are drawn together. This is not without its challenges and to some extent academics and practitioners are still finding their way with this. PaR comes originally from the world of fine art, where the artistic product is more tangible. Performance is much less so and there are issues and questions around documentation.

When we move beyond the artistic product of staged productions and begin to include artistic practice within the training situation it is even more complex as Simon Murray recognises 'researching training practices necessitates quite complex engagements with a number of different constituencies: tutor and student, researcher and intended recipients of the dissemination, the concrete nature of the practices being learned, and the historical and cultural contexts which enshrine them.' (Murray. 2011, 148) As most voice teachers' work takes place within the studio this will be an area that needs development and exploration. There is contention about the viability of studio based teaching being an appropriate site for PaR, especially within the conservatoire. Baz Kershaw rails against the conservatoire model as a site for PaR demanding a more open-ended engagement that can influence the artist practitioner as much as the student. When talking of PaR Kershaw says that he is not

thinking of the conservatoire model of the masterclass, where a set of knowledges is transferred from he/she who knows to those who are ignorant, although this does have its place in any dialogue between the academy and the professions. The artist-philosopher will deploy an ongoing, openended set of practices, within which the artist's knowing is potentially subject to the same transformative possibilities as the student's. (Kershaw. 2009, 22)

It is true that much conservatoire actor training does conform to the structure that Kershaw eschews; however, I believe that it is possible, even within the conservatoire, to engage in some areas of the training with an 'open-ended set of practices' and that such approaches are beneficial to the actors in training. Recently, I extended some more traditional conservatoire teaching of poetry by asking the question 'What happens if we now take a post-dramatic approach to these texts? What will happen if we discard the unity of the poetic form and, instead, approach it from a process of collage?' Experimenting in this way, beyond the traditional parameters, led to valuable insights around text, listening and dialogue that I am hoping will be later applied to work on scenes. This was, in a small way, an open ended exploration that was instigated by my reading of theory relating to post-dramatic texts. Voice practitioners who are going to do research through artistic practice-especially that which does not create a specific performance outcome-will need to be 
open to working from this "What happens if?" perspective. This may present challenges for curriculum design and will require flexibility and support from managers within the University Conservatoire sector. However, this way of approaching training has its advantages; it opens the potential for practitioners to learn alongside their students. This process of collaborative open ended teaching builds a more democratic learning environment and is one that I would warmly welcome.

\section{Proposing a Voice Studies PaR project.}

I am beginning to develop my own research practice in line with the PaR methodology outlined above. My main teaching role at Central is to lead the voice work on the BA Acting Collaborative and Devised Theatre Course. This course is unique in its philosophy and approach to actor training. The individual components of the training are not in themselves new; however, the philosophy and ethos of the course-coupled with a combination of psycho-physical training techniques and devised and collaborative practices, set within a longstanding and respected conservatoire-make for an innovative and dynamic context for actor training.

The course interrogates a number of areas of performance, theory, philosophy, and practice. The course seeks to place the actor at the centre of the creative process and challenges the hierarchical nature of traditional theatre practice where the actor serves the directors vision or concept. To date, the taught voice practices on the course have followed a reasonably traditional conservatoire form: practical voice work is based on the psycho-physical practice of Kristin Linklater; text work draws on the long-standing language-based approaches of practitioners such as Cicely Berry and Patsy Rodenberg; and accent/dialect work uses the traditional phonologically based standards common in most conservatoire training. Questions that are emerging through my practice and will be researched further include:

- What happens when the Linklater voice work engages with contemporary performance practices such as verbatim, intermedial and post-dramatic theatre?

- What happens to the language based approaches to text when they meet the multiple texts of devised, post dramatic and intermedial performances?

- How sustainable are the traditional conservatoire approaches to speech and accent learning when they meet the challenges of verbatim work, on a course that celebrates diversity and internationalism?

- How do voice practices yield to and accommodate the range of acting and movement disciplines within this innovative training context?

The work will continuously be documented and reviewed through film and journaling. In this practice I am beginning to engage with theory from related subjects such as performance studies and neuroscience. As in the examples of classroom based research above, my reading in these related areas has prompted me to ask questions within my teaching practice. This is an example of the multiple strand, rhizome process of research outlined by Nelson. It does not require me to become an expert in another discipline but allows me to seek out the resonances between other disciplines and my area of expertise, Voice Practice. Clearly, working in this way does require a new skill set. Thankfully PaR is well served with the aforementioned publications and a welldocumented history of evolution development. PARIP (Practice as Research in Performance), which Baz Kershaw was central to, was a five year research project by the University of Bristol that sought 'to investigate creative-academic issues raised by practice as research' (http://www.bris.ac.uk/parip/introduction.htm). These publications etc. are a good starting point for interested researchers. Institutions are also investing in supporting research initiatives in response to the REF agenda. As an early career researcher without a PhD this still feels like a leap into the unknown and without a long standing model for Voice Studies to adopt, my process will inevitably 
be a process of trial and error. However, I feel better able to learn the skills associated with a research methodology that reflects my practice than I am able to learn a new discipline, such as philosophy, from which to theorise my practice.

\section{Dissemination of PaR}

Outputs from PaR may include: conference presentations, PaR web-publications, e-books, symposia, and published articles. The dissemination of $\mathrm{PaR}$ is an area of ongoing development and discussion amongst academics and practitioners. Jonathan Pitches notes that passing on an embodied practice from person to person in the acting studio, is quite different to transferring that knowledge to the wider academic arena. 'It is one thing to 'record' the translation of knowledges from one practitioner to similar corporeal media, quite another to assume that writing alone can support this translation and sufficiently communicate it to others.' (Pitches. 2011, 142)

A useful example of the type of output that might be produced from PaR within Voice Studies is Jane Boston and Patricia Bardi's work on the Physical Voice in the Moving Body, which can be accessed via Central's International Centre for Voice website. (http://www.icvoice.co.uk/projects) Boston and Bardi have been exploring somatic voice practice in studio based work and this led to a public presentation/seminar. The website 'takes the form of a series of edited video frames and accompanying audio responses'. In exploring the website the viewer can experience the context and discussion of the presentation framed and reflected upon by accompanying critical commentary.

I will soon publish a similarly designed web page, looking at 'Performing Presences'. This will draw on a PaR workshop carried out with my colleague Sinéad Rushe, combining her teaching of Michael Chekhov technique with some of the Linklater principles and relating to some of the questions of presence discussed above.

These types of outputs currently present some challenges in terms of recognised publication and peer review, where options are limited. At the moment, the momentum for developing an adequate publication opportunities for PaR in Voice Studies may be lacking as the global voice community is strongly influenced by the US where PaR is, as yet, relatively unknown ${ }^{6}$. This is a problem that will need to be faced as the subject and practice grows. However, this publication problem is not limited to Voice Studies and should not be seen as a deterrent to carrying out this type of research as PaR is certainly accepted practice within arts based HE and very much accepted as part of the REF in the UK.

\section{Conclusion}

It is important that voice and speech practitioners in higher education see the current situation as an opportunity rather than a threat. There is an opportunity to add the knowledge held within practice based lineages to the growing subject of arts based Voice Studies. These lineages carry embodied knowledge from the pioneers of a relatively short history of voice practice. The pioneers who have developed this work have nurtured the embodied "know how" of voice, passing it on through teacher trainings and workshops; they have written the valuable "know what" texts that practitioners return to again and again; and they have often looked beyond practice to engage with wider philosophical and political debates that resonate with the subject of voice. PaR re-examines these lineages for an academic audience and continues to ask questions that relate to this broad and far reaching subject.

$\mathrm{PaR}$ allows and encourages practice to evolve and for doing and thinking to take place simultaneously. The placing of the conservatoire within a reflective framework that seeks new knowledge asks that practitioners continue to develop their discipline. It is important that research within Voice Studies does not solely feed a research agenda and it is my personal hope that, by way of Practice as Research, Conservatoires will be able to produce actors and performers with skills that are relevant to a rapidly evolving profession in an equally rapidly shifting global landscape. 


\section{References.}

Boston, Jane (2014) Poetic text in contemporary voice training: a repositioning, Voice and Speech Review, 8:2, 131-148, DOI: 10.1080/23268263.2014.906957

Bulman, James. (1996) Shakespeare, theory and performance. London: Routledge.

Brown, John (2010) An Independent Review of Higher Education Funding and Student Finance. https://www.gov.uk/government/uploads/system/uploads/attachment_data/file/31999/101208-securing-sustainable-higher-education-browne-report.pdf

Kershaw, Baz. (2009) Practice as Research: An Introduction in Practice-as-Research: in performance and screen. Basingstoke: Palgrave Macmillan.

Klocker, Natascha. (2012) Doing Participatory Action Research and Doing a PhD:

Words of Encouragement for Prospective Students, Journal of Geography in Higher Education, 36:1, 149-163, DOI: 10.1080/03098265.2011.589828

Linklater, Kristin. (1976) Freeing the natural voice. New York: Drama Book Publishers.

Murray, Simon. (2011) Researching Lecoq and Physical Theatres. Chapter 6.3 in Research methods in theatre and performance. Edinburgh: Edinburgh University Press.

Nelson, Robin. (2013) Practice as research in the arts : principles, protocols, pedagogies, resistances. Basingstoke: Palgrave Macmillan.

Pitches, Jonathan. (2011) Performer Training: Researching Practice in the Theatre Laboratory. Chapter 6 in Research methods in theatre and performance. Edinburgh: Edinburgh University Press.

Power, Cormac. (2008) Presence in Play: A critique of theories of presence in the theatre. Amsterdam: Rodopi.

REF (2011) Assessment Framework and Guidance on Submissions.

(http://www.ref.ac.uk/media/ref/content/pub/assessmentframeworkandguidanceonsubmissions/G OS\%20including\%20addendum.pdf.)

Riley, Rose. (2013) Why Performance Research? A US Perspective. Chapter 11 in Practice as Research in the Arts: Principles, Protocols, Pedagogies, Resistances. Basingstoke: Palgrave Macmillan.

Smith, Hazel. and Dean, Roger.T. (eds.) (2009) Practice-led Research, Research-led Practice in the Creative Arts. Edinburgh: Edinburgh University Press.

Werner, Sarah. 1996. Performing Shakespeare: Voice Training and the Feminist Actor. New Theatre Quarterly, 47: 249-258.10.1017/S0266464X00010241

Wilkins, Stephen, Shams, Farshid \& Huisman, Jeroen (2013) The decision making and changing behavioural dynamics of potential higher education students: the impacts of increasing tuition fees in England, Educational Studies, 39:2, 125-141, DOI: 10.1080/03055698.2012.681360 


\section{Wyness, Gill. 2010. Policy changes in UK higher education funding, 1963-2009. Department of Quantitative Social Science Working Paper no 10-15, London.}

\section{Notes}

${ }^{1}$ I use the term 'arts based Voice Studies' to indicate the study of voice practices within performance that are outside of areas such as voice medicine and vocal anthropology.

${ }^{2}$ In the United States, the issue of practitioner as researcher may not be a pressing one, but, as note 6 explains, PaR may provide part of the solution to the growing economic crisis in higher education there.

${ }^{3}$ It is important to note that in the UK there is no such thing as a liberal arts education. If a student at the age of 18 is accepted to study acting, they will only study acting subjects full-time for the entirety of their three year training.

${ }^{4}$ Action Research in Australia is known as Participatory Action Research or PAR, not to be confused with this article's focus, Practice as Research (PaR).

${ }^{5}$ Alfred Korzybski coined the expression in "A Non-Aristotelian System and its Necessity for Rigour in Mathematics and Physics", a paper presented before the American Mathematical Society at the New Orleans, Louisiana, meeting of the American Association for the Advancement of Science, December 28, 1931. (http://en.wikipedia.org/wiki/Map\%E2\%80\%93territory_relation)

${ }^{6}$ In the US practice and theory have existed alongside each other for a long time with parallel tracks to PhD and MFA. Promotion and tenure (there is no system of tenure in the UK) can be gained through professional creative work as well as through research outputs. However, this two-track system is coming under increasing pressure and may eventually be unsustainable. Nelson's book ends with a selection of essays giving perspectives from around the world and in her essay Why Performance Research? A US Perspective, Shannon Rose Riley suggests that 'There may be untapped potential for PaR strategies to help theatre programmes avoid being cut in the current economic crisis in the US...Marvin Carlson recently suggested that the 'movement' of Performance as Research might be a useful direction for a flailing and at-risk field of theatre in US higher education.' (Riley. 2013, 183) 